Original Research Article

\title{
Drug utilization pattern in dermatology outpatient department at a tertiary care hospital in Navi Mumbai
}

\author{
Arun Patil*, Darshana Dighe, Shrikrishna Kolte, Pradeep R. Jadhav, Y. A. Deshmukh
}

Department of Pharmacology, MGM Medical College and Hospital, Kamothe, Navi Mumbai, Maharashtra, India

Received: 27 December 2016 Accepted: 01 February 2017

\section{*Correspondence to:}

Dr. Arun Patil,

Email: dranpatil24@gmail.com

Copyright: (C) the author(s), publisher and licensee Medip Academy. This is an openaccess article distributed under the terms of the Creative Commons Attribution NonCommercial License, which permits unrestricted noncommercial use, distribution, and reproduction in any medium, provided the original work is properly cited

\begin{abstract}
Background: Skin diseases are common and cause a huge disease burden globally. Different class of drugs and combinational products are available in dermatology for treatment. Periodic prescription analysis in the form of drug utilization study can improve the quality of prescription and curb the menace of irrational prescribing. Aim and objective of the study were to study the prescribing pattern and drug utilization trends in Dermatology outpatient department at a tertiary care hospital in Navi Mumbai.

Methods: A cross-sectional, observational study was conducted over a period of three months in dermatology department of a tertiary care teaching hospital, Navi-Mumbai. A total of 102 adult patients visiting dermatology OPD were included and their prescriptions were analyzed with WHO prescribing indicators and additional indices.

Results: Analysis showed that the average number of drugs per prescription was 3.27. Percentage of drugs prescribed by generic name was $31.1 \%$. Percentage of drugs prescribed from National Essential drug list (NEDL) was $44.2 \%$. The commonest prescribed drugs were antihistaminics followed by antifungals. Oral tablets were the commonest prescribed dosage form.

Conclusions: Antihistaminics and antifungals dominated the prescribing pattern in this study with restraint on polypharmacy, but showed ample scope for improvement to prescribe generic and selection of essential drugs.
\end{abstract}

Keywords: Drug utilization, Dermatology, Prescribing pattern

\section{INTRODUCTION}

Drug utilization has been defined as the marketing, distribution, prescription and use of drugs in a society with special emphasis on the resulting medical and social consequences. The assessment of drug utilization is important for clinical, educational and pharmacoeconomic purposes. ${ }^{1}$ Drug utilization studies helps in the understanding of prescription pattern as well as the quality of prescription in terms of rationality, drug interactions and financial burden of disease. These studies have a favourable impact on improving the standards of treatment, identifying drug related problems and providing useful feedback to the clinicians. ${ }^{1-4}$

Drug utilization studies conducted across different regions of India in various disciplines of medicine have documented indiscriminate antibiotic usage, low generic prescribing, low selection and utilization of essential drug, thus raising the concern regarding rational use of drugs. $5-10$

Skin diseases are common and cause a huge disease burden globally. They have serious detrimental effect on quality of life by increasing the suffering in terms of physical, social, psychological as well as it increases financial burden as most of the skin diseases are chronic and requires longer duration of treatment. At the global level, skin conditions are the fourth leading cause of nonfatal disease burden. ${ }^{11}$

Primary and secondary cutaneous complaints are common. Allergy and itches problems are most widely observed in patients. ${ }^{11,12}$ Different classes of drugs and combinational products are available in dermatology, which are generally used in the treatment of skin diseases which are usually based upon the prescriber's knowledge, clinical experience and choice. ${ }^{13-15}$ 
Drug utilization studies conducted recently in dermatology across India have reported issues of high prescribing of branded drugs, low adoption of essential drug and polypharmacy, thus creating concern regarding the rational use of drugs in dermatology specialty. ${ }^{13-20}$ There exist paucity of data in literature on the drug utilization trends from this region; therefore this study was conducted to study the prescribing pattern and drug utilization trends in Dermatology outpatient department at a tertiary hospital in Navi Mumbai (Maharashtra).

\section{METHODS}

Permission from the Institutional Ethics Committee was taken before the initiation of the study. The present study was conducted in the Outpatient Department of Dermatology at Tertiary Care Teaching Hospital in Navi Mumbai.

It was a prospective, cross-sectional, quantitative preliminary study conducted over a period of three months. Prescriptions of patients attending dermatology OPD of a tertiary care teaching hospital, Navi Mumbai, were collected randomly from January 2016 to March 2016. Newly registered/ diagnosed adult patients from either sex who visited dermatology outpatient department were included. Hospitalized referral patients, repeated attendance and patients not consenting were excluded from the study.

The case record forms were used to record relevant data from the prescriptions/case papers of the enrolled participants which included, demographic profiles, diagnosis or pattern of skin disease, classes and drugs prescribed with their frequency and dosage form. Obtained information was then compiled and analyzed using World Health Organization (WHO) prescribing indicators, which included average number of drugs/ products per encounter, percentage of drugs prescribed by generic name, percentage of encounters with antibiotics prescribed, percentage of encounters with an injection prescribed, percentage of drugs prescribed from National Essential Drug List -NEDL and additional indices like commonest class / type of drugs prescribed and the various dosage form prescribed. ${ }^{1-3,21}$

\section{Statistical analysis}

Data was entered and analyzed with Microsoft Excel 2007. Descriptive statistics were performed. Values were expressed as actual numbers, percentage and mean with standard deviation.

\section{RESULTS}

In this study one hundred and two prescriptions $(n=102)$ were analyzed and the total number of drug products prescribed were three hundred and thirty four (334). Male were $56.86 \%(n=58)$, female were $43.14 \%(n=44)$ and the mean age of the participants was $28.92 \pm 13.5$ years.
Drugs were prescribed in various different dosage forms. Tablets $(47.8 \%)$ were the most commonly prescribed dosage form, followed by cream (17.8\%), ointment $(10.3 \%)$ and lotions $(7 \%)$.

\section{Prescribing pattern and drug utilization}

In this study, the average number of drugs per prescription was 3.27. Out of total prescribed drugs, $78.9 \%$ drugs were prescribed by brand name and only $31.1 \%$ by generic name, thus documenting inclination towards brand names. The percentage of drugs prescribed from National Essential Drug List/Formulary was $44.2 \%$. The percentage of encounter with antibiotic was $11.07 \%$ and percentage of encounters with injection was $1.98 \%$ which was on the lower end (Table 1).

\section{Table 1: Details of drug utilization} prescribing indices.

\begin{tabular}{|lll|}
\hline $\begin{array}{l}\text { Sr. } \\
\text { no. }\end{array}$ & WHO Prescribing Indices & Value \\
\hline 1 & Average number of drugs per encounter & 3.27 \\
\hline 2 & $\begin{array}{l}\text { Percentage of drugs prescribed by } \\
\text { generic name }\end{array}$ & $31.1 \%$ \\
\hline 3 & $\begin{array}{l}\text { Percentage of encounters with an } \\
\text { antibiotic prescribed }\end{array}$ & $11.07 \%$ \\
\hline 4 & $\begin{array}{l}\text { Percentage of encounters with an } \\
\text { injection prescribed }\end{array}$ & $1.98 \%$ \\
\hline 5 & $\begin{array}{l}\text { Percentage of drugs prescribed from } \\
\text { National Essential Drug List }\end{array}$ & $44.2 \%$ \\
\hline
\end{tabular}

Table 2: Different class of drugs prescribed in dermatology.

\begin{tabular}{|llll|}
\hline Sr. no & Class of drugs & Number & Percentage \\
\hline 1 & Antihistaminics & 75 & $22.46 \%$ \\
\hline 2 & Glucocorticoids & 43 & $12.87 \%$ \\
\hline 3 & Antibiotics & 37 & $11.08 \%$ \\
\hline 4 & Antifungals & 69 & $20.66 \%$ \\
\hline 5 & Antiviral agents & 9 & $2.69 \%$ \\
\hline 6 & Demelanising agents & 13 & $3.89 \%$ \\
\hline 7 & Immunomodulators & 15 & $4.49 \%$ \\
\hline 8 & Scabicides & 9 & $2.69 \%$ \\
\hline 9 & Comedolytics & 7 & $2.10 \%$ \\
\hline 10 & Emmolients & 14 & $4.19 \%$ \\
\hline 11 & Sunscreen lotion & 8 & $2.40 \%$ \\
\hline 12 & Vitamin supplements & 22 & $6.59 \%$ \\
\hline 13 & and antioxidants & & \\
\hline 14 & Keratolytic agents & 5 & $1.50 \%$ \\
\hline
\end{tabular}

During the study period the commonly prescribed classes of drugs are depicted in Table 2. Out of the total 334 prescribed drugs, Anti-histaminics constituted 22.46\% (75) and were the most commonly prescribed drugs followed by antifungals $20.66 \%$ (69). Among the total prescribed Antihistaminics, Levocetrizine (34) was 
prescribed commonly followed by Cetrizine (12), Loratidine (11), Fexofenadine (10) and Hydroxyzine (8) in this study. While among the prescribed Antifungals, Terbinafine (28) was the commonest prescribed followed by Clotrimazole (19), Ketoconazole (17) and Sertaconazole (5). The commonest antibiotic and glucocorticoid encountered were Doxycycline and Clobetasol respectively in this study.

\section{DISCUSSION}

The prescriptions reflect the overall attitude of the prescribing physicians along with their knowledge for the disease process and the pharmaco-therapeutic approach adopted for the disease or condition. The present study assessed the prescribing pattern and drug utilization trends in Dermatology outpatient department at a tertiary hospital in Navi Mumbai.

The average number of drugs per prescription in this study was 3.27. There was evidence of poly-pharmacy. Our findings are similar to studies which have documented polypharmacy with average drugs ranging from 3 to 5 per prescription. ${ }^{13,17,18,20}$ It is advisable to keep restraint on poly-pharmacy as it leads to risk of drug interactions, errors in dispensing and difficulty in taking dosage as per prescribed schedule.

The study documented lower prescribing drugs by generic name $(31.1 \%)$ reflecting inclination and preference of prescribers towards branded drugs. Prescribing by generic name is essential for economical cost effective utilization of drugs. However other studies in dermatology have documented prescribing drugs by generic names from $7 \%$ to $24 \%$, which were lower than the findings of our study. ${ }^{13-19}$

In this study, the percentage of encounters with antibiotics was $11.07 \%$. The antibiotic utilization was lower in this study in comparison to other dermatology studies. ${ }^{15,16,22}$ Higher prescribing of antibiotics leads to indiscriminate use, increases risk of drug resistance and adverse effects. The percentage of encounters with injection prescribed was $1.98 \%$ which was on the lower end and showing restraint on injections in comparison to other studies.

The percentage of drugs prescribed from National Essential Drug List/Formulary in this study was $44.2 \%$. In our study we found the prescribing of essential drugs from national essential drug list was higher in comparison to studies, which have documented $12 \%$ to $24 \%$ prescribing of essential drugs in dermatology. ${ }^{13-19}$ However, there is ample of scope for improvement and need to encourage dermatologist to prescribe from national essential drugs first. The World Health Organization emphasizes the prescribing of medicines as much as possible from the essential medicines list or hospital formulary, as medicines are selected for this list with due regard to disease prevalence and to the evidences of efficacy, safety and the cost.

In this study, we found that antihistaminic was the major class of drugs used by the dermatologist. Cetrizine and Levocetrizine were the commonly prescribed second generation antihistaminics which were similar to other studies. ${ }^{14,20}$ Studies conducted across India have shown similar trend of high antihistaminic prescribing in dermatology. ${ }^{13,14,16,17}$ The higher side of antihistaminic prescribing in this study seems to be justified due to its anti-allergic and antipruritic actions. This could be due to prevalence of dermatological disorders with related symptoms of itching/ pruritus (associated with allergy, fungal infection, scabies, eczema and dermatitis). However other studies have documented antibiotic and antifungal being the most commonly prescribed drugs. ${ }^{15,20,22}$ In our study, Terbinafine was commonly prescribed among the antifungal drugs. Terbinafine belongs to the group of allylamine, which noncompetitively inhibits fungal squalene epoxidase and exerts broad spectrum antifungal activity. Other studies have documented fluconazole being the commonly prescribed. ${ }^{13,14,16,20}$

In our study, we documented that, Oral tablets were the commonest dosage forms in comparison to topical agents which was similar to Pathak et al, Krishna et al and Rekha et al. ${ }^{13,17,22}$ Other studies have documented topical forms commonly prescribed in dermatology. ${ }^{18,20}$ Use of topical agents should be preferred for treating skin diseases as they have site specific action, less systemic absorption resulting in less side effects and convenient for patient use.

In light of the finding of this present study, following recommendation can be implemented for rational prescribing and rational use of drugs: 1) Adoption of essential drugs from National Essential Drug List, 2) Prescribing drugs from generic name instead of brand names, 3) Formulation of guidelines /policies related to appropriate use of drugs, 4) Initiative to prepare hospital based formulary and 5) Continuous supervision, audit and monitoring of prescription and providing feedback to health care provider.

\section{Limitation}

It was a cross-sectional quantitative study with limited sample size. The study duration was short and hence seasonal variation could influence the prescribing trend.

\section{CONCLUSION}

Antihistaminics and antifungals dominated the prescribing pattern in this study with restraint on polypharmacy, but showed ample scope for improvement in encouraging the dermatologist to prescribe by generic name and selection of essential drugs from National Essential Drug List to ensure rational use of drugs. 


\section{ACKNOWLEDGEMENTS}

Authors would like thank the Head of Department of Dermatology for the permission, support and cooperation.

Funding: No funding sources Conflict of interest: None declared

Ethical approval: The study was approved by the Institutional Ethics Committee

\section{REFERENCES}

1. World Health Organization (WHO) and International Network for Rational Use of Drugs. How to Investigate Drug Use in Health Facilities: Selected Drug Use indicators. Geneva, Switzerland: WHO; 1993.

2. Dukes MNG. Drug utilization studies: methods and uses. World Health Organization Regional Publications. European series; 45. Copenhagen, Denmark. Available from: http://apps.who.int/medicinedocs/documents/s21868e n/s21868en.pdf.

3. World Health Organization. Introduction to Drug Utilization Research. Oslo, Norway: WHO; 2003. Available from: http://apps.who.int/medicinedocs/en/d/Js4876e/

4. Lee D, Bergman U. Studies of drug utilization. In: Storm LB, editor. Pharmacoepidemiology. Chichester, UK: John Wiley and Sons; 2005:401417.

5. Jadhav PR, Moghe VV, Deshmukh YA. Drug Utilization Study in Ophthalmology Outpatients at a Tertiary Care Teaching Hospital. ISRN Pharmacology. 2013:768792.

6. Mirza NY, Desai S, Ganguly B. Prescribing pattern in a pediatric out-patient department in Gujarat Bangladesh Journal of Pharmacology. 2009;4(1):3942.

7. Ain MR, Shahzad N, Aqil M, Alam MS, Khanam R. Drug utilization pattern of antibacterials used in ear, nose and throat outpatient and inpatient departments of a university hospital at New Delhi, India. J of Pharmacy and Bioallied Sciences. 2010;2(1):8-12.

8. Kaur S, Rajagopalan S, Kaur N. Drug Utilization Study in Medical Emergency Unit of a Tertiary Care Hospital in North India. Emergency Medicine International; 2014:973578

9. Mittal N, Mittal R, Singh I, Shafiq N, Malhotra S. Drug Utilisation Study in a Tertiary Care Center: Recommendations for Improving Hospital Drug Dispensing Policies. Indian $\mathrm{J}$ of Pharmaceutical Sciences. 2014;76(4):308-14

10. Barot PA, Malhotra SD, Rana DA, Patel VJ, Patel KP. Drug utilization in emergency medicine department at a tertiary care teaching hospital: A prospective study. J of Basic and Clinical Pharmacy. 2013;4(4):78-81.
11. Hay RJ, Johns NE, Williams HC, Bolliger IW, Dellavalle RP, Margolis DJ, et al. The global burden of skin disease in 2010: an analysis of the prevalence and impact of skin conditions. J Invest Dermatol. 2014 Jun;134(6):1527-34.

12. Jain S, Barambhe MS, Jain J, Jajoo UN, Pandey N. Prevalence of skin diseases in rural Central India: A community-based, cross-sectional, observational study. J Mahatma Gandhi Inst Med Sci. 2016;21:1115.

13. Pathak AK, Kumar S, Kumar M, Mohan L, Dikshit H. Study of Drug Utilization Pattern for Skin Diseases in Dermatology OPD of an Indian Tertiary Care Hospital - A Prescription Survey. J Clin Diagn Res. 2016 Feb;10(2):FC01-5.

14. Kumar J, Chandra S, Sinha HK. Utilization pattern of drugs among dermatological outpatients in a tertiary care hospital of eastern India. International Journal of Pharmacological Research. 2016;6(9):297-302.

15. Vineeta D, Sharad P, Ganachari MS, Geetanjali S, Santosh S. Assessment of Drug Prescribing Pattern and Cost Analysis for Skin Disease in Dermatological Department of Tertiary Care Hospital: An Interventional Study. J Pharma Co Vigil. 2016;4(3):211.

16. Mohamed Saleem TK, Dilip C, Nishad VK. Assessment of Drug Prescribing Patterns in Dermatology Outpatient Department in a Tertiary Care Hospital, Malabar, Kerala. Indian J of Pharmacy Practice. 2012;5(3):62-8.

17. Krishna J, Singh A, Goel S, Roy A, Singh AK, Yadav KP. Clinical pharmacological study of prescribing pattern of dermatological drugs from atertiary care teaching hospital. Indian J. Sci. Res. 2015;6(2):41-5.

18. Tikoo D, Chopra SC, Kaushal S, Dogra A. Evaluation of Drug Use Pattern in Dermatology as a Tool to Promote Rational Prescribing. JK science. 2011;13(3):128-31.

19. Maini R, Verma KK, Biswas NR, Agrawal SS. Drug utilization study in dermatology in a tertiary hospital in Delhi. Indian J Physiol Pharmacol. 2002 Jan;46(1):107-10.

20. Minocha KB, Bajaj S, Gupta K, Gupta M. A Clinicopharmacological study of out-patient prescribing pattern of dermatological drugs in an Indian tertiary hospital. 2000;32(6):384-5.

21. National List of Essential Medicines of India 2015. Ministry of Health and Family Welfare, Government of India. Available from: http://www.pharmaceuticals.gov.in/NLEM.pdf.

22. Rekha MS, Rekha MB, Rajeshwari, Naidu P. Study on Prescribing Pattern in Skin Department of a Teaching Hospital. Indian Journal of Public Health Research and Development. 2015;6(4):141-5.

Cite this article as: Patil A, Dighe D, Kolte S, Jadhav PR, Deshmukh YA. Drug utilization pattern in dermatology outpatient department at a tertiary care hospital in Navi Mumbai. Int $\mathrm{J}$ Basic Clin Pharmacol 2017;6:559-62. 